\title{
AC 2010-1710: INTERACTIVE LEARNING USING A SPIRAL APPROACH IN A LARGE REQUIRED FIRST-YEAR MECHANICAL ENGINEERING CLASS
}

\section{Stacy Bamberg, University of Utah}

Stacy J. Morris Bamberg is an assistant professor of Mechanical Engineering at the University of

Utah. She received her S.B. and S.M. in Mechanical Engineering from the Massachusetts Institute of Technology, and her Sc.D. in Medical Engineering from the joint Harvard/MIT Division of Health Sciences and Technology. She teaches the required freshman design sequence, the required junior mechatronics sequence, and electives in musculoskeletal functional anatomy for engineers and medical instrumentation and physiology. She is interested in the use of technology in the classroom and improving student outcomes through hands-on and interactive experiences.

\section{Debra Mascaro, University of Utah}

Debra J. Mascaro is the Director of Undergraduate Studies in Mechanical Engineering at the University of Utah. She holds a B.A. in Physics from Gustavus Adolphus College in St. Peter, $\mathrm{MN}$ and a Ph.D. in Materials Science and Engineering from the Massachusetts Institute of Technology. She teaches freshman design and senior-/graduate-level classes in microscale engineering and organic electronics.

\section{Robert Roemer, University of Utah}

Robert B. Roemer is currently a professor of Mechanical Engineering at the University of Utah. He received his B.S. degree from the University of Wisconsin, Madison, and his M.S. and Ph.D. degrees from Stanford University. He teaches courses in engineering design, and is interested in integrating the use of design projects and active learning throughout the curriculum to improve engineering education. 


\title{
Interactive Learning Using a SPIRAL Approach in a Large Required First-Year Mechanical Engineering Class
}

\begin{abstract}
$\underline{\text { Abstract }}$
The use of active learning is being implemented in a large, required first-year Mechanical Engineering two-course sequence that is part of a larger curricular sequence that implements a Student-driven Pedagogy of Integrated, Reinforced, Active Learning (SPIRAL) approach to learning. The educational gains that are possible from active learning are difficult to realize in courses with large enrollments and students with widely varying backgrounds, especially in these financially difficult times in large public universities. To overcome these difficulties we have begun using advances in communication technology, computer aided engineering (CAE) software, Computer Automated Manufacturing (CAM), and rapid prototyping tools to increase the amount of "hands on" interactive learning in our new sequence of two, large, required, firstyear courses. Specifically, we are experimenting with: classroom student response systems ("clickers") to enhance small group interactive discussions and peer-based learning; CAE/CAM software and rapid prototyping technology to allow students to design and manufacture sophisticated components without overwhelming our machine shop resources; in-class demonstrations of engineering principles with oversized components and associated interactive student team discussions and clicker responses; inverting the lecture/homework paradigm by providing lectures on YouTube and using in-class activities to work on homework/example problems in small groups in class; elimination of some textbooks when lecture material can suffice in order to save the students money; hands-on laboratory experiments using inexpensive, mass-produced components made using the same rapid prototyping tools available to the students; and the use of semester- or year-long design projects integrated with the course material and constructed within stringent budget restrictions.
\end{abstract}

\section{Introduction}

Many studies ${ }^{\text {e.g. } 1,2}$ have demonstrated that cooperative learning with interactive projects significantly enhances learning, retention and application of material, helps nontraditional students learn, and motivates engineering students to remain in school, as compared with traditional techniques. Bruner presented a "'spiral curriculum' that turns back on itself at higher levels" through repetition at ever-increasing depths of knowledge. ${ }^{3}$ This pedagogy has been adapted for a large required first-year Mechanical Engineering class, using a Student-driven Pedagogy of Integrated, Reinforced, Active Learning (SPIRAL) approach, and is now being used in a second course, both of which are funded by the National Science Foundation as part of a four-course sequence. The large class size, the wide range of educational backgrounds of our students (since our introductory class has few pre-requisites), and their associated range of learning styles ${ }^{1}$ bring special challenges to implementing an interactive learning curriculum. Fortunately, many of the high tech advances produced by engineers in the recent decades can be applied to engineering education to provide students with interactive learning opportunities. Our techniques can be readily applied to other engineering disciplines (with an appropriate shift in focus) or common first-year curricula. The organizational syllabus for this class showing lecture topics, lab topics, and assignment due dates is available in Appendix 1. 
Three companion papers give descriptions of our initial experiences with: the overall plan and goals of the two-year program, ${ }^{4}$ the integration and spiraling of concepts and tools, ${ }^{5}$ and engineering communication skills. ${ }^{6}$ Those papers also indicate some of the modifications and changes we have already made based on our initial experiences.

\section{Implementation of Interactive Learning}

More than 140 students were enrolled in the first semester of this new first-year course, (ME 1000), making interactive learning a challenge in the classroom - especially given the few required prerequisites and wide range of students' backgrounds and learning styles. The format of this class is two 80-minute lectures (taught by professors) plus one three-hour lab (taught by teaching assistants) each week. The previous class content and instruction have been completely reworked to apply the use of active, cooperative, and design-project based learning approaches. These replace the prior, primarily traditional, lecture format that typically had a significantly reduced emphasis on how to apply the material in a practical context and a corresponding lack of interactive learning.

The interactive learning experiences have been designed to address a large number of learning styles. Five categories of learning styles have been previously identified: ${ }^{1}$ a) skills-based, b) lecture-based, c) inquiry-based, d) technology-enhanced, and e) individual vs. group. A number of different activities (Fig. 1, inspired by Bransford ${ }^{1}$ ) have been identified and implemented, and many of these address multiple learning styles.

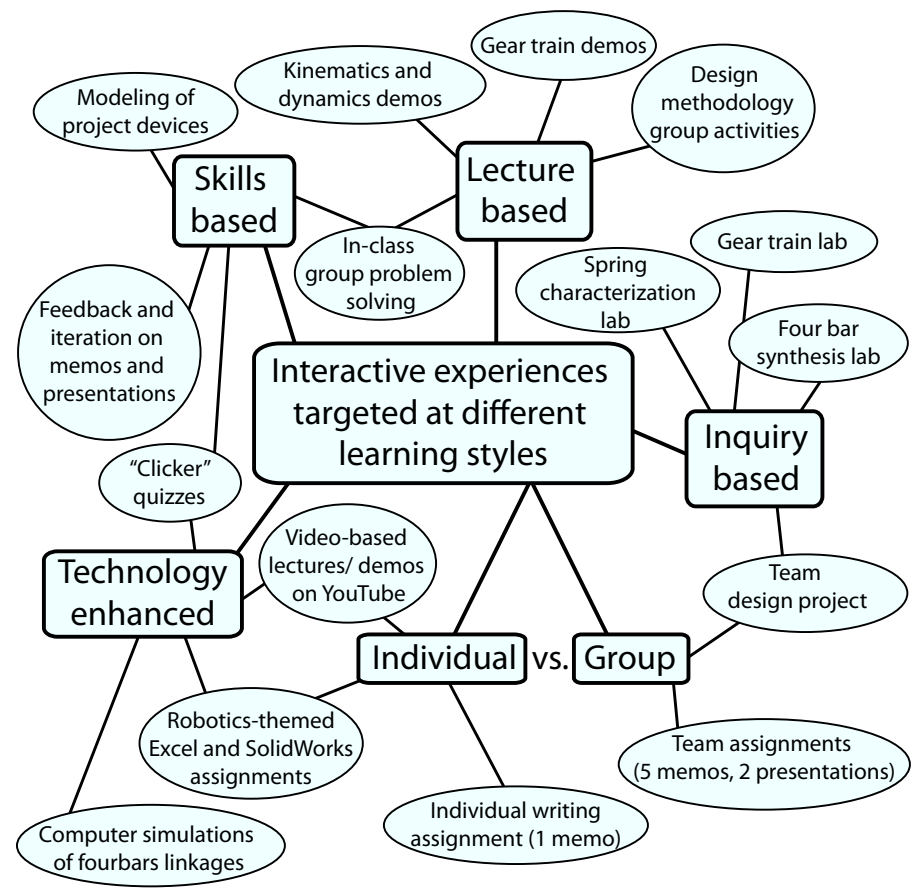

Figure 1. First semester interactive learning methods used to target a variety of learning styles.

For example, many of the lectures in the first half of the class focus on design methodology. Using the problem statement "create interactive kinematics and dynamics demos," examples of the design methodology topic were started in lecture, and then the students work in small groups to complete the work. The class reconvenes to discuss the results, and, where possible, the 
students provide their results using their student response systems ("clickers"). Prototypes of the demos were then used throughout the semester in the lecture.

To reach as many students as possible, multiple interactive learning activities are used to target different learning styles for each topic. When pairwise comparison charts (PCCs) were introduced as a design tool, students worked through the PCC for the "create interactive kinematics and dynamics demos" design example in small groups, and then entered their results with their clickers. The aggregate PCC results were used to carry the example forward in lecture. A selection of the lecture slides from this lecture, including the clicker questions used to collect the results from the students, and the example of the group work are available in Appendix 2. Next, students were required to work in their project teams to develop PCCs for their design project, and then to present these results in a written memo. Students received feedback on their memos from writing consultants (focused on the technical writing aspects) and the instructors (focused on the use of the design methodology tools) to improve their skills in these areas.

Similarly, when gears were introduced during the latter half of the semester, a large demo in the front of the classroom (Fig. 2a) was used to introduce the concept of simple and compound gear ratios. This was followed by hands-on activities in the lab (Fig. 2b) where students worked in pairs to analyze gear trains and design gear trains to achieve specified gear ratios. Additionally, students completed homework problems on gears individually as part of the Excel homework (the memo and attachments corresponding to this lab are available in Appendix 3).
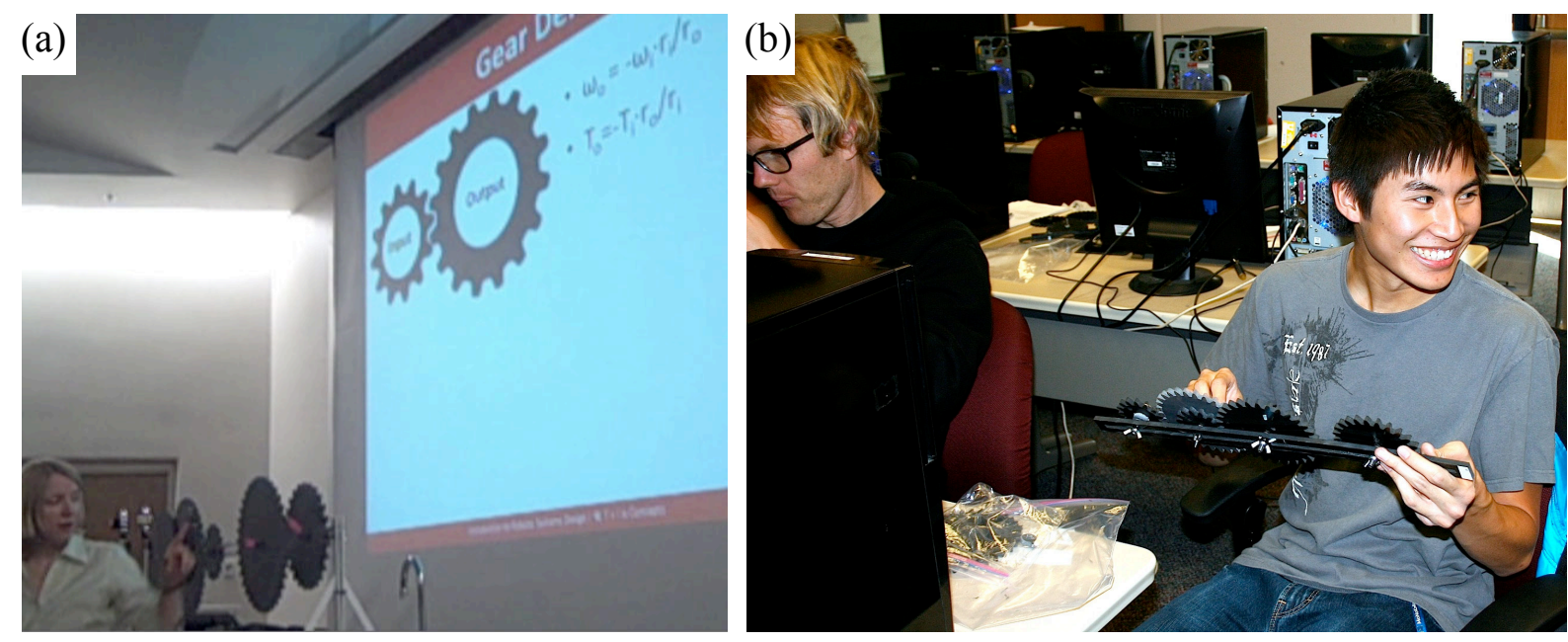

Figure 2. Interactive learning methods used to teach simple and compound gear trains, (a) Large classroom demo, (b) Small hands-on lab experiment.

The interactive tools used in this first-semester course include the following:

Student Response Systems: These systems ("clickers") allow the students to get immediate feedback on their understanding of material, using either multiple choice or numerical answer questions. A series of quiz questions were presented at the start of lecture to cover the previous lecture material and the reading assignment. Multiple choice quiz questions were graded with +10 points for the correct answer, -10 points for the incorrect answer, and 0 points for answering "I don't know" (always the last option); this grading scheme was implemented to discourage 
guessing. Additional questions were included within the lecture, with all answers worth +5 points, for instance to: a) assess students' understanding of material that had just been presented, b) acquire students' input on design problems (as described above), or c) allow students to "vote" on the most likely outcome of a short problem after working in small groups. Using clickers in these ways addresses technology-enhanced and skills-based learning styles.

Inverting the Lecture Paradigm: The widespread availability of YouTube allows course instructors to present highly focused lecture material in a dynamic manner that allows students to easily replay the lectures to learn the material (for examples, see a development of a problem statement and an objectives tree: http://www.youtube.com/watch? $\mathrm{v}=$ hife $5 \mathrm{rllCc} 4$, or a lecture on explicit finite differences: http://www.youtube.com/watch?v=APxdABK0Jws). This frees up classroom time for more active learning activities (partially based on the YouTube content). For example, we provided students with a video of a brainstorming session that developed an objectives tree for a design problem along with additional material related to objectives trees; second, we provided a detailed video description of using explicit finite differences to solve a physics problem, including examples in Excel. The use of video instruction addresses technology-enhanced and individual learning styles that allow students to watch the material numerous times at their own pace.

CAE and Rapid Prototyping Tools: Computer-Aided Engineering (CAE) and rapid prototyping tools were used in the class in two distinct ways. First, the students learned CAE (using SolidWorks ${ }^{\circledR}$ ) in the laboratory portion of this course, and we require every student to design a fourbar linkage in SolidWorks ${ }^{\circledR}$, with each linkage subsequently manufactured on a waterjet cutter for use in their team design project (each student's linkage had to perform "a significant function" in their design project, which was a robotic volleyball competition). Second, we used $\mathrm{CAE}$ and the waterjet cutter to manufacture components of the class demonstrations and the hands-on lab experiments. This gave students an opportunity to investigate parts made on the waterjet cutter before finalizing their designs. The use of CAE and rapid prototyping tools enabled interactive activities for all of the learning styles.

Oversized Class Demonstrations plus In-Class Group Problem Solving: Large (i.e. visible from the back of our large classroom) visual demonstrations were developed that involved active participation by student volunteers. These included: a) An "egg-zooka" for modeling and predicting the trajectory of an egg propelled by springs to demonstrate physics concepts ( $\mathrm{F}=\mathrm{ma}$ in particular) and explicit finite difference techniques; b) A pulley with two wheel sizes to demonstrate physics concepts ( $\mathrm{T}=\mathrm{I} \alpha$ in particular); c) Fourbar linkage models to demonstrate different classes and inversions; and d) Gear trains to investigate gear ratios in simple and compound gear trains (with swappable gears), as shown in Fig 2a. These all had associated example problems that were solved by the students working in small groups (2-4 students) during the lecture. Several other lectures also included small group problem solving to get the students thinking and discussing the issues at hand. These address skills-based, lecture-based and group learning styles.

Hands-On Laboratories: The hands-on laboratories were developed to give students a chance to investigate the concepts discussed in lecture on their own, and included: a) a spring characterization lab to determine spring constants of a compression spring, extension spring and rubber band, b) a fourbar lab to build different classes of linkages and investigate the inversions 
of their resulting models, c) a prototyping lab to make foam-core models of linkages for their designs, and d) a gear train lab (see Fig. 2b) to build and analyze specified simple and compound gear trains and to design simple and compound gear trains to achieve specified gear ratios. These hands-on laboratories address inquiry-based and group learning styles.

Team-Based Design Projects: In the first semester, we purposely assign a project that requires students to design as many devices as the number of students on the team (ideally teams have four students). This year the project was to design four devices to serve, bump, set, and spike in an end of semester "Volley-bot" competition. Teams are free to design as a group or individually; we have found that this approach helps moderate the students' anxieties about team work in this first-semester engineering class, as it allows students to easily split up the design if they choose. Of course, this means their involvement with their team is decreased, but this decrease is compensated for since: a) the design assignments and competition are such that the students must communicate and work with their team members at several other stages, and b) they are exposed to teamwork multiple times throughout our curriculum. This flexibility also allows us to easily adjust each team's workload if the team size changes (i.e. from four to three students, which happens frequently during this first-semester class). In the "Volley-bot" competition, this adjustment was accomplished by having similar requirements for the bump-bot and set-bot, and thus three-person teams were required to design and build a serve-bot, a combo bump-/set-bot, and a spike-bot. These design projects address skills-based, inquiry-based, technology-enhanced, and both individual and group learning styles.

At the time of this writing, we are implementing the second-semester course and are making the following changes based on our first-semester experiences and student feedback.

Student Response Systems: We received a lot of positive feedback from the students regarding the clickers. Students really like the immediate feedback on questions and discussion of the right answer, as well as the anonymity. They extremely disliked the negative points associated with the incorrect answer for multiple-choice questions. We will continue to use this technology in a similar fashion to the first semester, but we will modify our grading to +10 points for the correct answer, -2 points for the incorrect answer, and +4 points for answering "I don't know" (always the last option). This will still provide an incentive to answer "I don't know" rather than guessing, without wiping the points of one correct response with one incorrect response.

Inverting the lecture paradigm: Student feedback was very positive on the videos, and we plan to include as many as we can in the spring semester as well. These take a lot of time to prepare, so we will likely continue to implement these over the next several years until we have a catalog of videos associated with each class.

CAE and Rapid Prototyping Tools: Students will be taught advanced CAE methods (again, using SolidWorks ${ }^{\circledR}$ ) labs and will have access to the waterjet cutter for their projects. In addition, each team will be required to each design and manufacture a small part using fused deposition modeling (FDM). We also plan to continue to use both the waterjet and FDM to make components for class demonstrations and hands-on lab experiments.

Oversized Class Demonstrations plus In-Class Group Problem Solving: Our focus in the spring shifts to electromagnetic actuators, and we plan to again include oversized class demonstrations. 
We will continue our efforts to include small group problem solving on a regular basis to stimulate discussion, as this was successful in the first semester.

Hands-on Laboratories: Hands-on laboratories planned for the spring include hand-drawing (to develop this valuable skill), motor characterization (to determine the torque-speed curve for a DC permanent magnet motor), introductory circuits and sensor labs to teach the students the skills required for their design project, and metrology labs to prepare them for more advanced manufacturing labs during the second year.

Team-Based Design Projects: In this second-semester course, we assign a project that requires each team to design a single device to complete multiple tasks in an effort to force students to work as a team in their design. The project is a biathlon where the device must drive around a curved track, and shoot two ping-pong balls from different positions ("standing" and "prone"). Each device must include at least one DC motor and one solenoid. Infrared sensors will be used to start and stop the device, and touch sensors will be used to identify the course locations for shooting the ping-pong balls. (Students, who are learning MATLAB ${ }^{\circledR}$ programming during this second-semester course, will be provided with skeleton code for controlling their devices.)

\section{$\underline{\text { Assessment }}$}

Three outcomes will be assessed over the next several years: a) students' performance on final exam questions, b) students' retention of knowledge, measured at the start of the junior year with an exam in the Mechatronics class (started this year, so that changes can be tracked), and c) retention of students, measured by tracking the names of students who eventually register for the Mechatronics class, indicating that these students have received upper-division status in the ME program. Outcomes $\mathrm{b}$ and $\mathrm{c}$ cannot be evaluated completely until several years have passed, but the current status will be discussed.

\section{a) Students' Performance on Final Exam Questions}

Our primary measure of direct assessment is a comparison of students' performance on final exam questions from Fall 2009 (the first offering of our revamped class) to Fall 2008 (taught in a traditional lecture style). Both final exams were "competency-based" exams given in the computer lab, with one third of the points each for questions using two different engineering software programs (in this class, SolidWorks ${ }^{\circledR}$, which was taught in the labs, and Excel ${ }^{\circledR}$, which was taught on the homework assignments and via self-paced learning). The remaining one third of the points were a paper exam covering the design content of the class, as well as mechanisms, teamwork, and communications. The 2008 and 2009 final exams were of similar length and difficulty (both exams were quite long and challenging), and the scores for both years are summarized in Table 1. (The final exams were not returned to students in either Fall 2008 or in Fall 2009 so that we can continue to use these questions with minimal concern that students are aware of the test content.) The Delta column represents the 2008 average score subtracted from the 2009 average score; a positive change indicates higher scores in 2009, while a negative change represents lower scores in 2009.

Students performed similarly on the SolidWorks ${ }^{\circledR}$ and the Excel® sections of the exams in both 2008 and 2009. The significant change in the teaching of these two subjects was that for 
Table 1. Student performance on the final exam.

\begin{tabular}{|l|c|c|c|c|}
\hline Topic & Year & Average & Std Dev & Delta \\
\hline \hline \multirow{2}{*}{ Design (1/3 of final exam) } & 2008 & $59.6 \%$ & $17.1 \%$ & $+13.2 \%$ \\
\hline \multirow{2}{*}{ SolidWorks (1/3 of final exam) } & 2009 & $72.9 \%$ & $17.7 \%$ & \\
& 2008 & $71.9 \%$ & $21.3 \%$ & $-2.9 \%$ \\
\hline \multirow{2}{*}{ Excel (1/3 of final exam) } & 2009 & $69.0 \%$ & $25.0 \%$ & \\
& 2008 & $48.0 \%$ & $22.8 \%$ & $+0.5 \%$ \\
\hline \multirow{2}{*}{ Fourbars (part of Design) } & 2009 & $48.5 \%$ & $25.5 \%$ & \\
\hline \multirow{2}{*}{ Design concepts (part of Design) } & 2008 & $53.1 \%$ & $35.4 \%$ & $+33.3 \%$ \\
& 2009 & $86.5 \%$ & $26.5 \%$ & \\
& 2008 & $48.9 \%$ & $27.7 \%$ & \multirow{2}{*}{$+21.2 \%$} \\
\hline
\end{tabular}

spreadsheets we discontinued use of a book for Excel ${ }^{\circledR}$ and replaced it with a small number of videos/lectures. The SolidWorks ${ }^{\circledR}$ instruction was similar in both years. The major changes in interactive learning were in the Design portion of the class, and a corresponding change of $+13 \%$ is seen in the scores for that section of the exam.

We were also able to compare two sub-groups of questions on the Design portion of the final exam. First, there were three questions about fourbar linkages that were identical on the two exams (calculating Grashof condition and identifying a specific link). This had a $+33 \%$ change, which is gratifying but expected given the changes in teaching style and increased content. In 2008 , there were one and a half lectures on fourbar linkages, accompanied by a set of homework problems and encouragement to use a fourbar on the design project. In 2009, there were two lectures on fourbar linkages, which included the large-scale demonstrations in lecture, a longer set of homework problems, a graphical synthesis lab followed by modeling and animation in SolidWorks, a hands-on lab exploring different Grashof conditions and inversions, a prototyping lab to build linkages, and required use of a fourbar in the final project. Thus, in addition to changing the teaching style, we increased the amount of time covered on this topic.

The second group of questions included one question covering tolerances in dimensioning (this was covered in a half lecture both years, but in 2009 this lecture involved small group discussion and answers via clickers) and two questions regarding decision matrices (both years, students were required to use decision matrixes for their team design project; in 2008, decision matrices were taught only using a reading assignment, while in 2009 they were covered in lecture using small group discussion and answers via clickers). The $+21 \%$ change is again gratifying but expected given the changes in teaching style.

\section{b) Students' Retention of Knowledge}

While seeing an improvement in students' performances on the final exam is very encouraging, our ultimate goal is to improve students' overall knowledge. To assess whether we are able to make an impact on students' long-term understanding of the material, we developed a 32 question multiple choice quiz. This quiz was administered to junior students in our ME 3200 Mechatronics class, which has as its prerequisites all of the various classes that will be incorporated into our new two-year series. We will observe whether an improvement in the performance of the junior students on this quiz occurs over the next several years. For 
comparison purposes this year, we also had the freshmen take the quiz; the results are shown in Table 2 . The $\%$ Respondents column shows the percentage of students enrolled in the class who participated in the quiz. The quiz was graded as follows: 10 points for a correct answer, -10 points for an incorrect answer, and 0 for answering "I don't know;" thus, the maximum points available were 320 .

Table 2. Student performance on the competency quiz.

\begin{tabular}{|c|c|c|c|c|}
\hline Student Group & Evaluation & \% Respondents & Average & Std Dev \\
\hline ME 1000 (first-year) & Fall 2009 (end) & $73.4 \%$ & $71.0 \%$ & $10.8 \%$ \\
ME 3200 (third-year) & Fall 2009 (start) & $81.4 \%$ & $42.9 \%$ & $17.2 \%$ \\
\hline
\end{tabular}

The freshmen students outperformed the juniors on the competency exam. This is probably mostly due to having just learned the material, since the score for the freshmen is from the end of the fall semester. However, it may also be due in part to a better understanding of the scoring. As the freshmen were tested at the end of the semester, they were very used to our scoring system that penalizes wrong answers (to discourage guessing) and rewards students for admitting "I don't know." This can be seen by looking at the maximum and minimum scores: in ME 3200 the max score was 245 and the min score was -45 , while in ME 1000 the max score was 320 and the min score was 110 . The higher max score for ME 1000 students likely results from the recent acquisition of the knowledge, while the higher min score for ME 1000 students likely indicates that the freshmen were less likely to guess and more likely to answer "I don't know"-which is one of the behavioral changes that we would like to encourage.

We will continue to administer the competency quiz at the start of ME 3200 to track changes in our students' retention of the knowledge that they should be acquiring through these new courses for their upper division coursework.

\section{c) Retention of Students in the Program}

Data from the last five full academic years was used to investigate our current student retention levels. The student IDs of students who passed (grade of C- or higher) our introductory (ME 1000) class during the last five years in either the fall or spring semester were compared to the IDs of students who have achieved upper division status during the same time period (including Fall 2009 semester). Upper division status indicates that these students have reached the junior level, and is measured using the enrollment lists from our ME 3200 class. The results are shown in Table 3.

Our current retention is around $50 \%$. The majority of the students who eventually achieve upper division status do so within two years, but as the older data from 04/05 and 05/06 indicates, we have a large group of students who take more time (the numbers to the right of the gray boxes). The makeup of our "commuter campus" student population is such that students are very likely to be working full or part time, and/or to take a leave of absence after starting school (e.g. for a religious mission). We also have a handful of transfer students each year who need to take our ME 1000 class, but are ready for upper division status the following year (the numbers to the left of the gray boxes). 
Table 3. Retention of students from first-year enrollment to third-year enrollment; shaded boxes indicate the semester in which the students in a particular academic year are expected to be third-year students.

\begin{tabular}{|c|c|c|c|c|c|c|c|c|c|}
\hline & & \multicolumn{6}{|c|}{ ME 3200 Semester } & \multirow[b]{2}{*}{$\begin{array}{l}\text { Total } \\
3200 \\
\end{array}$} & \multirow[b]{2}{*}{$\begin{array}{l}\text { Percent } \\
\text { Retained }\end{array}$} \\
\hline $\begin{array}{l}\text { ME } 1000 \\
\text { Year: }\end{array}$ & $\begin{array}{l}\text { Total } \\
1000\end{array}$ & $\begin{array}{l}\text { Fall } \\
04 \\
\end{array}$ & $\begin{array}{l}\text { Fall } \\
05 \\
\end{array}$ & $\begin{array}{l}\text { Fall } \\
06\end{array}$ & $\begin{array}{l}\text { Fall } \\
07 \\
\end{array}$ & $\begin{array}{l}\text { Fall } \\
08 \\
\end{array}$ & $\begin{array}{l}\text { Fall } \\
09 \\
\end{array}$ & & \\
\hline F04/S05 & 146 & 0 & 6 & 38 & 12 & 8 & 4 & 68 & $46.6 \%$ \\
\hline F05/S06 & 146 & 0 & 0 & 9 & 33 & 19 & 15 & 76 & $52.1 \%$ \\
\hline F06/S07 & 139 & 0 & 0 & 0 & 6 & 42 & 18 & 66 & $47.5 \%$ \\
\hline F07/S08 & 150 & 0 & 0 & 0 & 1 & 3 & 42 & 46 & $30.7 \%$ \\
\hline F08/S09 & 133 & 0 & 0 & 0 & 0 & 0 & 1 & 1 & $0.8 \%$ \\
\hline Total: & 714 & & & & & & Total: & 257 & $36.0 \%$ \\
\hline
\end{tabular}

We would like to see our retention numbers increase well beyond the $50 \%$ level. We will continue to track the students who pass our first-year courses and who enroll in our ME 3200 class to see whether we can identify a correlation in increased retention over the next several years. As our initial group of students approach graduation, we will inquire about their experience in these new classes during their senior exit interviews.

\section{$\underline{\text { Conclusion }}$}

Our goal is to aid student learning and improve student retention of material using interactive projects, as well as to increase retention of students in our program. A summary of the different techniques implemented for each learning style is shown in Table 4. Implementing interactive

Table 4. Techniques used to address different learning styles.

\begin{tabular}{|l|l|}
\hline Learning Styles & Techniques \\
\hline Skills based & $\begin{array}{l}\text { Student-response systems ("clickers") } \\
\text { Computer-Aided Engineering (CAE) and rapid prototyping tools } \\
\text { Oversized class demonstrations plus in-class group problem solving } \\
\text { Team-based design projects }\end{array}$ \\
\hline Lecture based & $\begin{array}{l}\text { Computer-Aided Engineering (CAE) and rapid prototyping tools } \\
\text { Oversized class demonstrations plus in-class group problem solving }\end{array}$ \\
\hline Inquiry based & $\begin{array}{l}\text { Computer-Aided Engineering (CAE) and rapid prototyping tools } \\
\text { Hands-on laboratories } \\
\text { Team-based design projects }\end{array}$ \\
\hline Individual & $\begin{array}{l}\text { Inverted lecture paradigm } \\
\text { Computer-Aided Engineering (CAE) and rapid prototyping tools } \\
\text { Team-based design projects }\end{array}$ \\
\hline Group & $\begin{array}{l}\text { Computer-Aided Engineering (CAE) and rapid prototyping tools } \\
\text { Oversized class demonstrations plus in-class group problem solving } \\
\text { Hands-on laboratories } \\
\text { Team-based design projects }\end{array}$ \\
\hline $\begin{array}{l}\text { Technology } \\
\text { enhanced }\end{array}$ & $\begin{array}{l}\text { Student-response systems ("clickers") } \\
\text { Inverted lecture paradigm } \\
\text { Computer-Aided Engineering (CAE) and rapid prototyping tools } \\
\text { Team-based design projects }\end{array}$ \\
\hline
\end{tabular}


teaching and learning methods requires a large investment in terms of time, but can be done relatively inexpensively by taking advantage of resources such as clickers (software and teaching hardware are free when adopted for a large class), YouTube for video hosting, and existing rapid prototyping equipment in our college to inexpensively manufacture large-scale demos for lectures and small-scale hands-on demos for labs.

We are encouraged by our final exam results showing an increased understanding of the design concepts and other material covered during the lecture portion of this class. We plan to continue to develop our techniques and apply them to the other components of this class (teaching SolidWorks in the laboratories and Excel on the homework). We also hope to see an increase in students' retention of the material taught in these courses by the time they reach their junior year, and at the same time, we hope to improve our retention of students beyond our current level of around $50 \%$.

Following successful implementation of our curriculum, we plan to work to help other departments implement it, in part by applying for a CCLI Phase 2 grant to continue our work. Our techniques can be applied to directly to other Mechanical Engineering departments, as well as schools with common first year curriculums and other engineering departments, by using the same techniques but shifting the focus to discipline-appropriate problems.

\section{Acknowledgments}

We enthusiastically thank the National Science Foundation for funding our course development through a Course Curriculum and Laboratory Improvement Phase 1 grant, titled "Design Based Spiral Learning Curriculum" (DUE-0837759). We are also grateful to Dean Richard Brown, the VP for Academic Affairs David Pershing and our Dept. Chairs Kent Udell (former) and Tim Ameel (current) for their additional support. This work would not have been possible without the hard work of our Teaching Assistants, Travis Steele, Dante Bertelli, and Mohamad Mollaei, and our colleagues Kyle Simmons, Susan Sample and April Kedrowicz.

\section{Bibliography}

[1] Bransford J, National Research Council (U.S.). Committee on Developments in the Science of Learning., and National Research Council (U.S.). Committee on Learning Research and Educational Practice., How people learn : brain, mind, experience, and school, Expanded ed. Washington, D.C.: National Academy Press, 2000.

[2] Lohman JR, "Special Issue: The Art and Science of Engineering Education Research," Journal of Engineering Education, 2005.

[3] Bruner JS, The Process of Education, Harvard University Press, Cambridge MA, 1982.

[4] Roemer RB, Bamberg SJM, Kedrowicz A, Mascaro DJ, “A SPIRAL Learning Curriculum in Mechanical Engineering," Paper submitted for presentation at the $117^{\text {th }}$ Annual Conference of the American Society for Engineering Education, Louisville, KY, June 2010.

[5] Mascaro DJ, Bamberg SJM and Roemer R, "Integration and Reinforcement of Engineering Skills Beginning in the First-Year Design Experience," Paper submitted for presentation at the $117^{\text {th }}$ Annual Conference of the American Society for Engineering Education, Louisville, KY, June 2010. 
[6] Simmons K, Sample S and Kedrowicz A, "Prioritizing Teamwork: Promoting Process and Product Effectiveness in a Freshman Engineering Design Course," Paper submitted for presentation at the $117^{\text {th }}$ Annual Conference of the American Society for Engineering Education, Louisville, KY, June 2010.

[7] Felder RM and Brent R, The ABCs of Engineering Education: ABET, Bloom's Taxonomy, Cooperative Learning, and so on. Proceedings ASEE Conference, 2004, Session 1375. 
Appendix 1 (p. 1 of 2): Detailed Syllabus for ME 1000

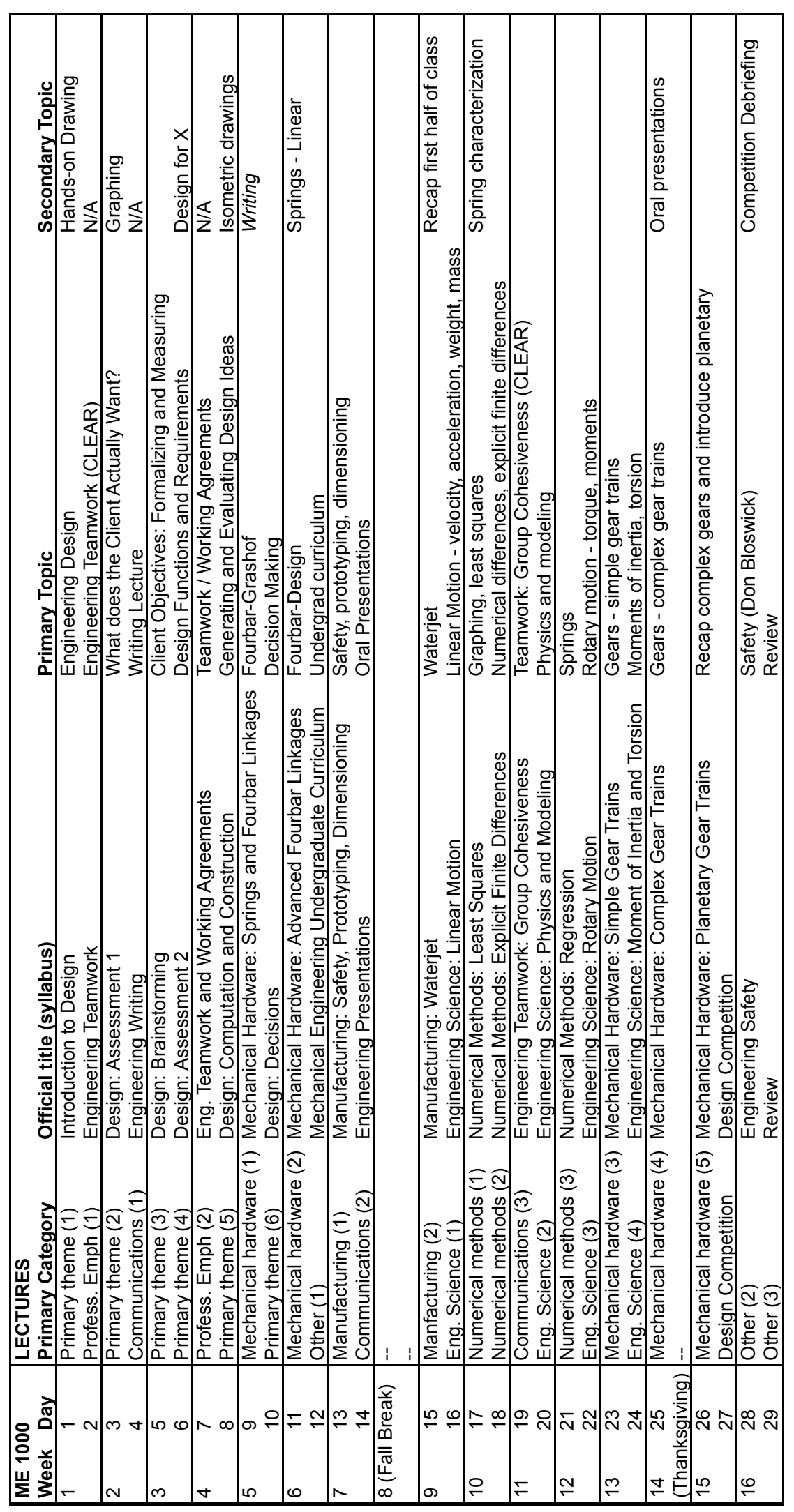


Appendix 1 (p. 2 of 2): Detailed Syllabus for ME 1000

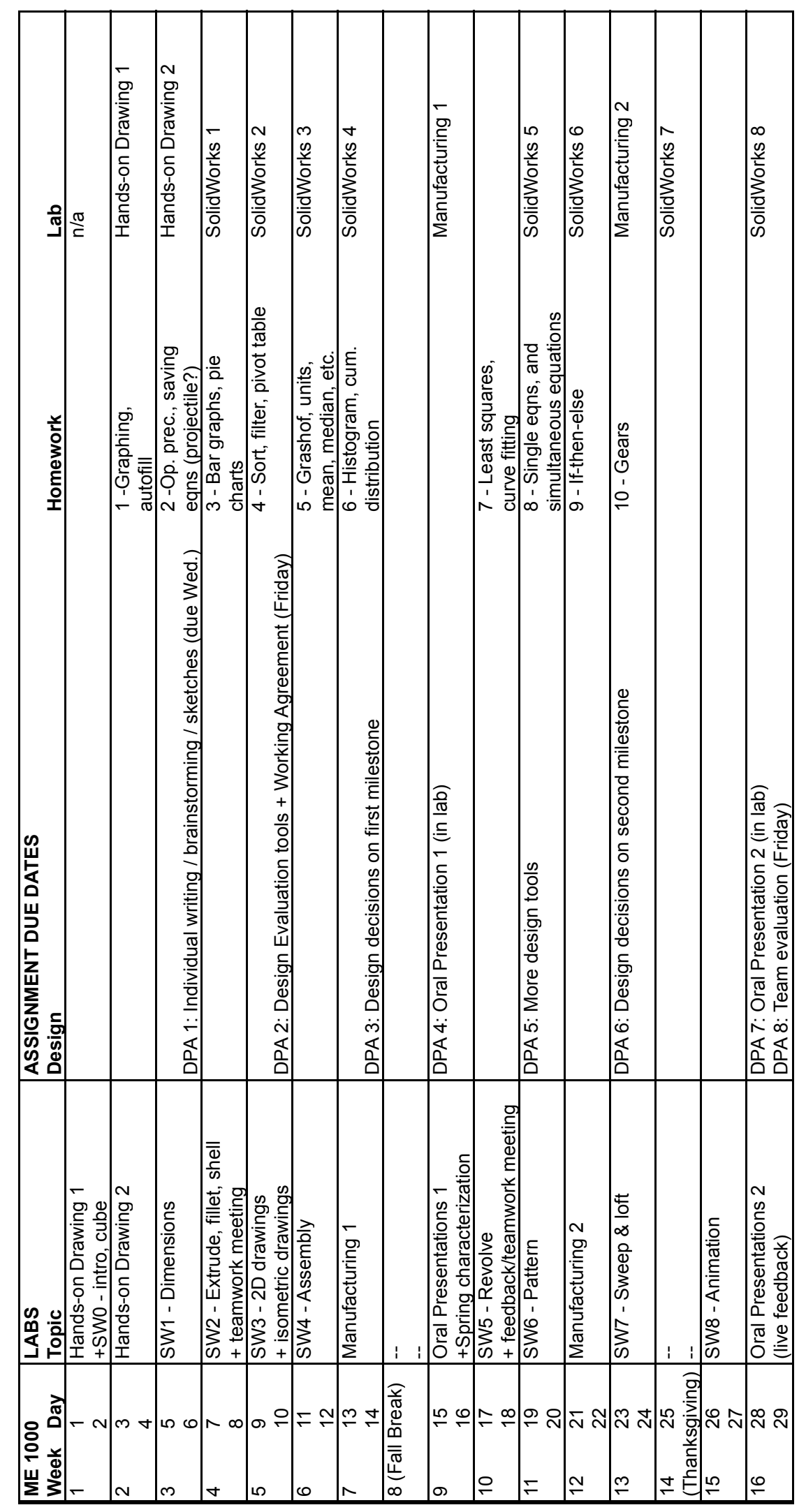


Appendix 1 (p. 1 of 2): Lecture Slides from PCC Example

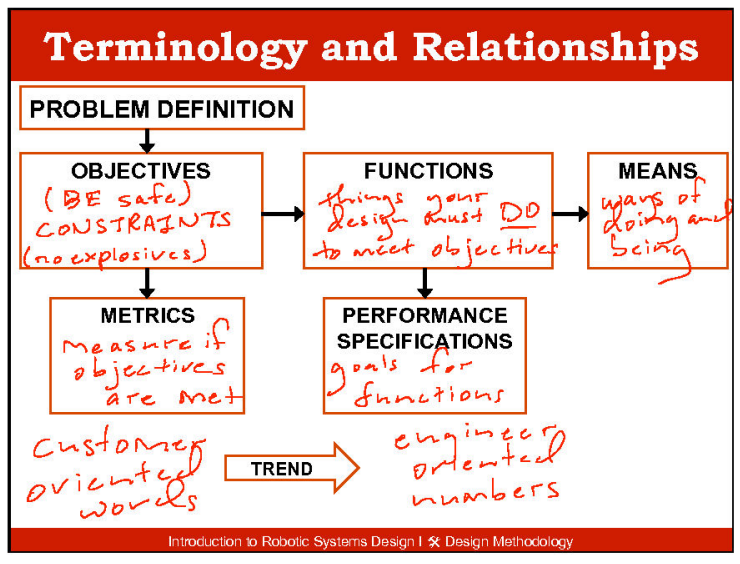

\section{Design Methodology Tools}

- Organizing Objectives

Objectives Trees

- Rank Ordering Objectives

Pair-wise Comparison Charts (PCC)

- Generating New Design Combinations

Morphological Charts

- Deciding Among Alternative Designs Decision Matrices

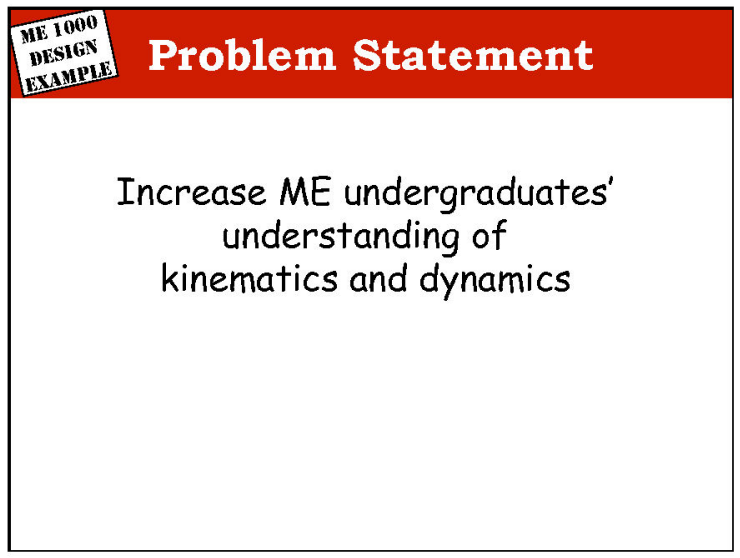

\section{Kinematics 85 Dynamics}

- Both analyze the motion of objects

- Kinematics Dynamics

-Analysis of motion of - Relationship between an object without motion considering causes of objects and the $x=\frac{1}{2} a t^{2}+v_{i} t \quad$ causes of motion

$$
\begin{aligned}
& F=m a \\
& T=I \alpha
\end{aligned}
$$

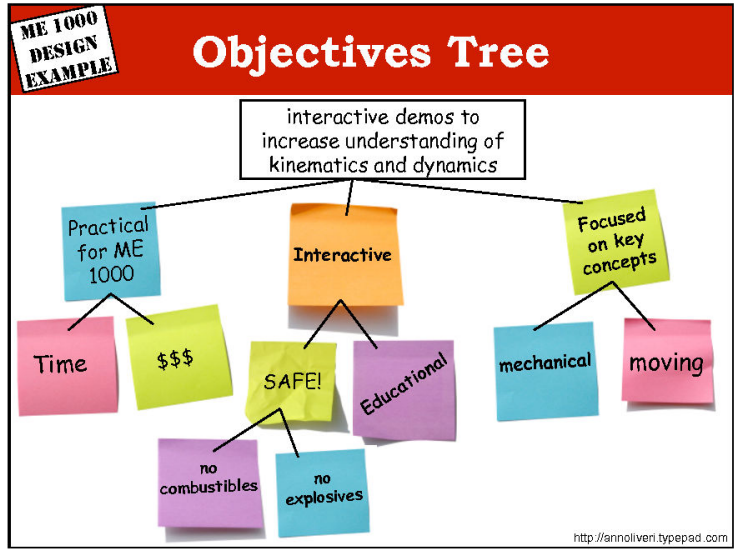

\section{Pairwise Comparison Charts}

- PCCs help you understand the trade-offs involved in the design objectives

- PCCs help your team "rank order" the objectives eminating from a common node and at the same level in your Objective Tree

- PCC rankings are subjective rankings

- PCCs help structure your meetings and keep your discussions "on track"

- PCCs should be applied to the highest level objectives first, and then applied "down the tree" 
Appendix 1 (p. 2 of 2): Lecture Slides from PCC Example

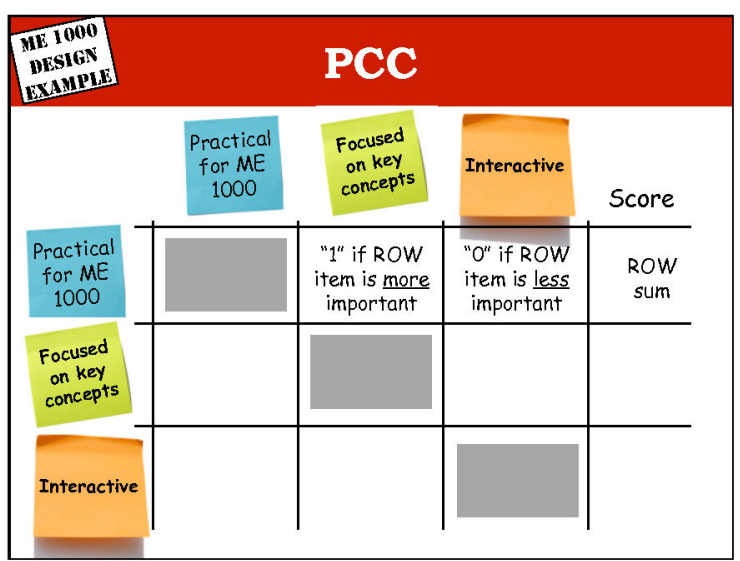

\section{Which objective is more important?}

1. Being practical for ME 1000

2. Being interactive
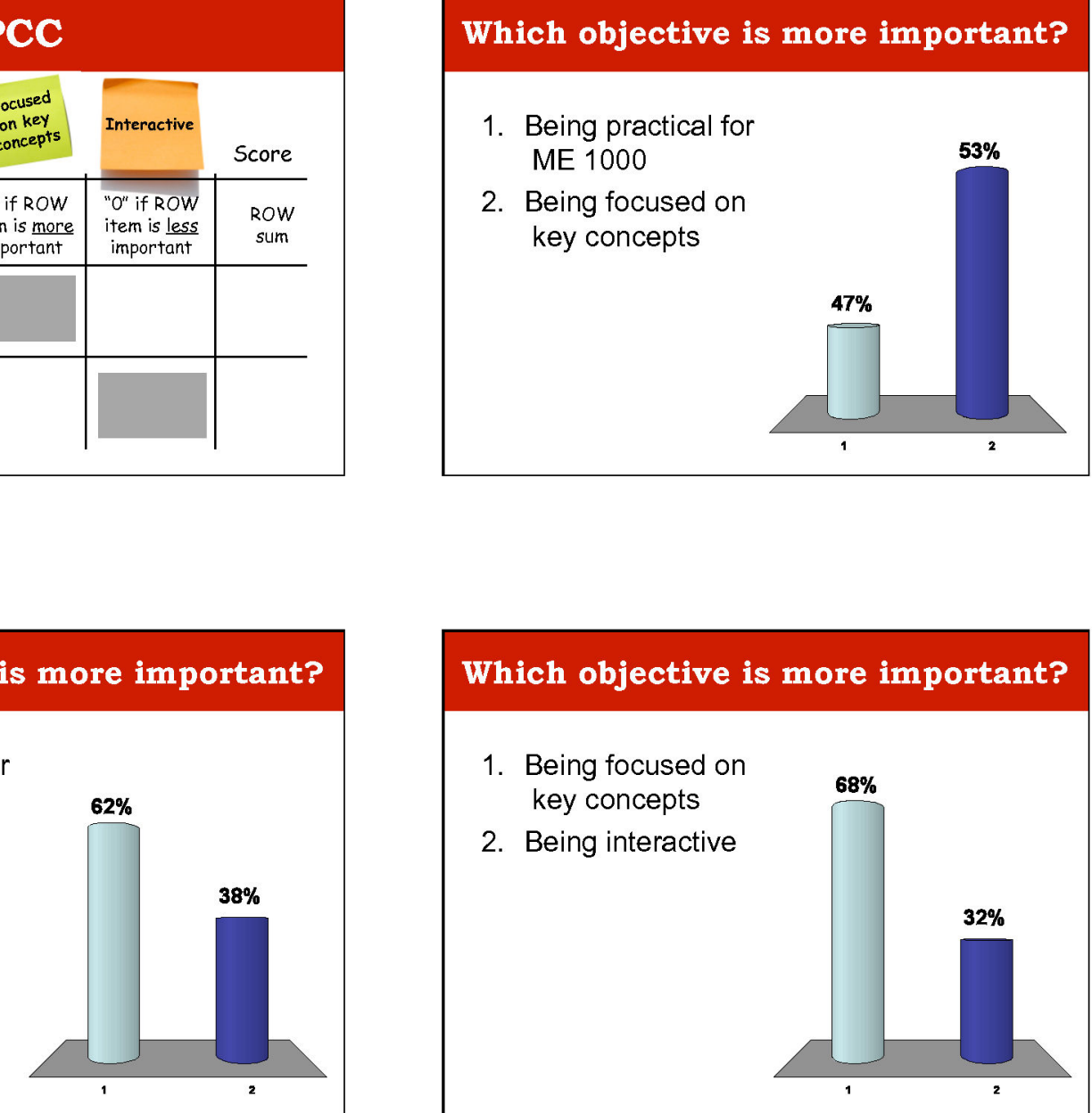

\section{Which objective is more important?}

1. Being focused on key concepts

2. Being interactive

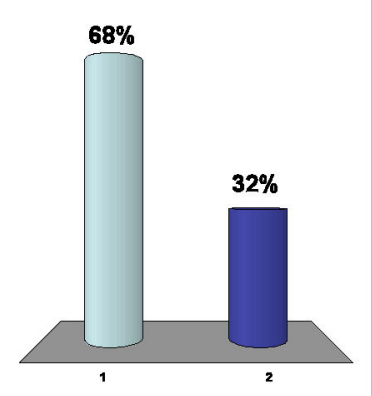

\begin{tabular}{|c|c|c|c|c|}
\hline & $\begin{array}{c}\text { Practical } \\
\text { for ME } \\
1000\end{array}$ & $\begin{array}{l}\text { Focused } \\
\text { on key } \\
\text { concepts }\end{array}$ & Interactive & Score \\
\hline $\begin{array}{c}\text { Practical } \\
\text { for ME } \\
1000\end{array}$ & & 0 & 0 & 0 \\
\hline $\begin{array}{l}\text { Focused } \\
\text { on key } \\
\text { concepts }\end{array}$ & 1 & & 1 & 2 \\
\hline Interactive & 1 & 0 & & 1 \\
\hline
\end{tabular}


ME EN 1000 Memo

\begin{tabular}{ll}
\hline TO: & ME EN 1000 Students \\
FROM: & Dr. Debra Mascaro and Dr. Stacy Bamberg \\
DATE: & November 16, 2009 \\
RE: & Laboratory 12 Assignment: Gears and Waterjet \\
CC: & Jungwoo Park, Devon Newman, Adam Howell, and Lynn \\
& Yang (Lab TAs) \\
ATTACHMENTS: & 2 (ME1000_Lab12-1Gears.pdf, ME1000_Lab12- \\
& 2Assignment.pdf) \\
\hline
\end{tabular}

\section{Introduction}

Gear trains are used in many machines to transmit rotation. In this lab you will learn how angular velocity and torque change depending on the gear ratios and the configuration of gears.

\section{Body}

In a simple gear train, two or more gears, each mounted on its own shaft, are mated together. The overall gear ratio is equal to the ratio (diameter or number of teeth) of the input to output gears. A compound gear train is one in which at least one pair of gears share a shaft and rotate with the same angular velocity. The gear ratio is the product of the driver teeth (or diameters) divided by the product of the driven teeth (or diameters). The objectives of Lab 12 are to:
A. Measure the gear ratios of simple gear trains having zero, one or two "idler" gears
B. Measure the gear ratios of two different compound gear trains
C. Learn to design gear trains that have specific gear ratios and directions
D. Receive feedback on your design notebook
E. Cut your volleybot linkages and other parts on the waterjet

The instructions for Lab 12 are to:

1. Come to WEB 208 (computer lab).

2. Work in pairs to carry out the gear experiments described in Attachment 1 [ME1000_Lab12-1Gears.pdf ]. Provide the requested information on Attachment 2 [ME1000_Lab12-2Assignment.pdf] and hand this in to the supervising TA when you are finished.

3. Show your Design Notebook to the TA that is supervising the gear portion of the lab.

4. When it is your team's turn, go to MEB 1311 and wait outside of the shop until the waterjet TA is ready for you. Bring printouts of the dimensioned drawings of your linkages and other parts to be cut on the waterjet.

5. Wear safety glasses at all times while in the shop.

DEPARTMENT OF MECHANICAL ENGINEERING, UNIVERSITY OF UTAH PAGE 1 OF 1 
6. Watch the TA cut your linkages and other parts with the waterjet. Your team will have 30 minutes on the waterjet.

\section{Conclusion}

Gear trains are very useful for changing torque and angular velocity. The majority of motors will provide you with high angular velocity and low torque, and you will typically need to use a gear train to achieve the appropriate torque (with a resulting change in angular velocity) for your application.

DePartment of Mechanical EngINEERING, UNIVERSity of UtAH

PAGE 2 OF 2 


\section{ME 1000: INTROdUCTION To RobotiC SySTEMS DESIGN I LAB 12, ATTACHMENT 1 -GEARS}

This laboratory assignment will allow you to explore gear trains and learn how angular velocity and torque change depending on the gear ratios and the configuration of gears.

\section{A. Materials and General Instructions}

1. You will receive the following materials from the TA, to be shared by you and a partner, as shown in Figure A1:
a. 2 each of four gear sizes ( 35 teeth, 30 teeth, 25 teeth, and 15 teeth)
b. 4 bolts $(1 / 4 "-20$ thread, $11 / 2$ " length)
c. 4 nuts $(1 / 4 "-20$ thread)
d. 4 wingnuts $(1 / 4 "-20$ thread $)$
e. 4 pins
f. 6 spacers
g. 1 guide

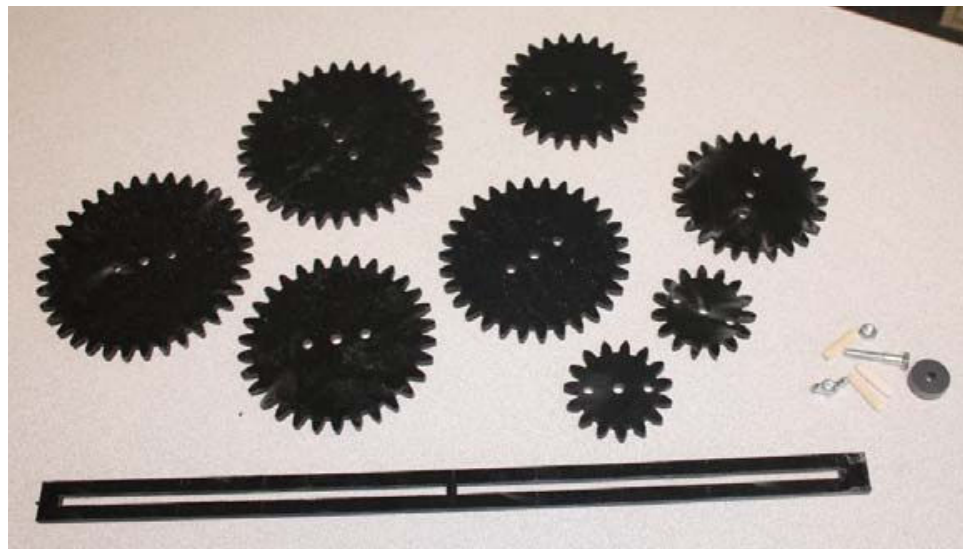

Figure A1. Materials for gear experiments.

2. To assemble the gear train:

a. Put a bolt through a spacer and then through a gear.

b. Add a nut to secure the gear, making sure that the gear can rotate freely.

c. Next insert the bolt through the slot in the guide, and attach the wingnut on the backside of the guide to fasten the shaft (bolt) in place as shown in Figure A2.

d. For compound gears, use the wooden pins to connect two gears together, and use spacers as necessary to properly position the gears.

e. The pins can also be used to help you keep track of the rotation of the gear.

DePARTMENT OF MEChaniCAL ENGINEERING, UnIVERSITY OF UtAH

PAGE 1 OF 4 


\section{ME 1000: INTRODUCTION to RoBotiC SySTEMS DESIGN I}

LAB 12, ATTACHMENT 1 -GEARS

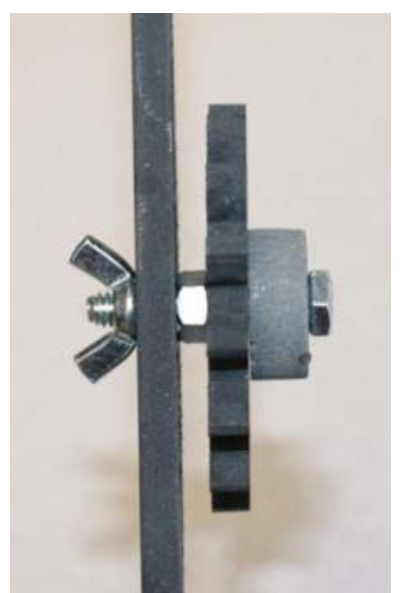

Figure A2. Assembling the gears.

3. For all directions below, the input gear will be the leftmost gear and the output gear will be the rightmost gear.

4. In general, the parameters of interest in investigating gears are angular velocity and torque. Since average angular velocity is rotation (angle) divided by time, you can measure the rotation of the input and output gears over the same amount of time to compare these directly.

5. Enter your answers on Attachment 2 and turn in Attachment 2 at the end of lab.

\section{B. Simple Gear Trains}

\section{Two Gears}

a. Find a gear with 30 teeth $(\mathrm{N}=30)$ and a gear with 15 teeth $(\mathrm{N}=15)$.

b. Put these gears on the guide $(\mathrm{N}=30$ on the left, $\mathrm{N}=15$ on the right) so that they are intersecting and can both rotate freely.

c. Rotate the input gear (on the left) one revolution $\left(360^{\circ}\right)$.

d. Enter the number of revolutions made by the output gear (on the right) on Attachment 2. Use a plus sign to indicate that the rotation is in the same direction and a minus sign to indicate that the rotation is in the opposite direction.

e. Calculate the gear ratio from the number of teeth (as discussed in lecture on 11/17), and show your calculations on Attachment 2.

DePARTMENT OF MEChaniCAL ENGINEERING, UniVERSity OF UtAH

PAGE 2 OF 4 


\section{ME 1000: INTRODUCTION to RoBotiC SySTEMS DESIGN I LAB 12, ATTACHMENT 1 -GEARS}

\section{2. "Idler" Gear}

a. Move the output gear from the previous step to the right, and place a gear with 35 teeth in the middle (from left to right, you should now have $\mathrm{N}=30, \mathrm{~N}=35, \mathrm{~N}=15$ ).

b. Set up these gears on the guide so that they intersect with their neighbor and can all rotate freely.

c. Rotate the input gear (on the left) one revolution $\left(360^{\circ}\right)$.

d. Enter the number of revolutions made by the output gear (on the right) on Attachment 2. Use a plus sign to indicate that the rotation is in the same direction and a minus sign to indicate that the rotation is in the opposite direction.

e. Calculate the gear ratio from the number of teeth (as discussed in lecture on 11/17), and show your calculations on Attachment 2.

\section{Two "Idler" Gears}

a. Move the output gear from the previous step to the right, and place a gear with 25 teeth to its left (from left to right, you should now have $\mathrm{N}=30, \mathrm{~N}=35, \mathrm{~N}=25, \mathrm{~N}=15$ ).

b. Set up these gears on the guide so that they intersect with their neighbor and can all rotate freely.

c. Rotate the input gear (on the left) one revolution $\left(360^{\circ}\right)$.

d. Enter the number of revolutions made by the output gear (on the right) on Attachment 2. Use a plus sign to indicate that the rotation is in the same direction and a minus sign to indicate that the rotation is in the opposite direction.

e. Calculate the gear ratio from the number of teeth (as discussed in lecture on 11/17), and show your calculations on Attachment 2.

\section{Compound Gear Trains}

\section{Example 1}

a. Take all of the gears off the guide.

b. Put a 30 tooth gear at the far left on the guide.

c. Put one of the 15 tooth gears to the right of this 30 tooth gear (so that they intersect), and put the other 30 tooth gear on top of this 15 tooth gear. Use a pin to connect these two together so that they will rotate with the same angular velocity.

d. Rotate the input gear (on the left) one revolution $\left(360^{\circ}\right)$.

e. Enter the number of revolutions made by the output gear (the 30 tooth gear on the right) on Attachment 2. Use a plus sign to indicate that the rotation is in the same direction and a minus sign to indicate that the rotation is in the opposite direction.

f. Calculate the gear ratio from the number of teeth (as discussed in lecture on 11/17), and show your calculations on Attachment 2. 


\section{ME 1000: INTRODUCTION to RoBotiC SySTEMS DESIGN I \\ LAB 12, ATTACHMENT 1 -GEARS}

\section{Example 2}

a. Use your set up from the previous step.

b. Use a spacer to elevate the other 15 tooth gear so that it intersects with the 30 tooth gear on the right.

c. Rotate the input gear (on the left) one revolution $\left(360^{\circ}\right)$.

d. Enter the number of revolutions made by the output gear (the 15 tooth gear on the right) on Attachment 2. Use a plus sign to indicate that the rotation is in the same direction and a minus sign to indicate that the rotation is in the opposite direction.

e. Calculate the gear ratio from the number of teeth (as discussed in lecture on 11/17), and show your calculations on Attachment 2.

\section{Designing Gear Trains}

1. Take all of the gears off the guide.

2. Next, work with your partner to design the five gear trains described below. Include your gear ratio calculations on Attachment 2. Sketch your designs in the space provided on Attachment 2, and then build them to check that they work.

a. Design $\mathrm{A}$ : design a gear train such that the output gear rotates $-1.2 \mathrm{x}$ for each 1 revolution of the input gear.

b. Design B: design a gear train such that the output gear rotates $+1.4 \mathrm{x}$ for each 1 revolution of the input gear.

c. Design C: design a gear train such that the output gear rotates $+2.8 \mathrm{x}$ for each 1 revolution of the input gear.

d. Design D: design a gear train such that the output gear rotates $-2.4 \mathrm{x}$ for each 1 revolution of the input gear.

e. Design E: design a gear train such that the output gear rotates $-6.533 \mathrm{x}$ for each 1 revolution of the input gear.

DEPARTMENT OF MECHANICAL ENGINEERING, UnIVERSITY OF UTAH

PAGE 4 OF 4 
Appendix 3 (p. 7 of 9): Sample Lab Handouts

ME 1000: INTRODUCTION TO RoBotic SYSTEMS DESIGN I

LAB 12, ATTACHMENT 2 - GEAR ASSIGNMENT

Name:

uNID:

Partner's Name:

Partner's uNID:

B1. Simple Gear Trains: No Gearing

Output ratio:

Gear ratio calculation:

B2. Simple Gear Trains: Idler Gear

Output ratio:

Gear ratio calculation:

B3. Simple Gear Trains: Two Idler Gears

Output ratio:

Gear ratio calculation:

C1. Compound Gear Trains 1:

Output ratio:

Gear ratio calculation:

C2. Compound Gear Trains 2:

Output ratio:

Gear ratio calculation:

DePARTMENT OF MECHANICAL ENGINEERING, UNIVERSITY OF UtAH

PAGE 1 OF 1 
Appendix 3 (p. 8 of 9): Sample Lab Handouts

ME 1000: INTRODUCTION to RobotiC SySTEMS DESIGN I

LAB 12, ATTACHMENT 2 - GEAR ASSIGNMENT

\section{D2. Designing Gear Trains (show gear calculation and sketch for each)}

a. Design:

b. Design:

c. Design:

DEPARTMENT OF MECHANICAL ENGINEERING, UNIVERSITY OF UTAH

PAGE 2 OF 2

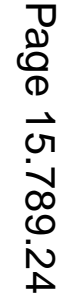


Appendix 3 (p. 9 of 9): Sample Lab Handouts

ME 1000: INTRODUCTION to RobotiC SySTEMS DESIGN I

LAB 12, ATTACHMENT 2 - GEAR ASSIGNMENT

d. Design:

e. Design:

DEPARTMENT OF MECHANICAL ENGINEERING, UNIVERSITY OF UTAH

PAGE 3 OF 3

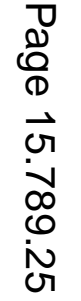

